\section{Best Free}

\section{Reference}

Websites

\section{Eighteenth Annual List}

\section{Emerging Technologies Section (ETS)}

Contributing members: Ashley Rosener and Paul Victor Jr., Co-Chairs; Christine Barnes; Georgia Baugh; Ava Brillat; Jessica Cerny; Allyssa Guzman; Laura Eileen Hall; Brian Kooy; Yaniv Masjedi; Autumn Mather; Sue McFadden; Sheena Sewell; Jeremy Walker; and Andrea Hill.
W elcome to the eighteenth annual "Best Free Reference Websites" list. It is hard to believe that this project has been around since the late 1990s. In 1998, the Machine-Assisted Reference Section (MARS) of RUSA appointed an ad hoc task force to develop a method of recognizing outstanding reference websites. The task force became a formal committee at the 2001 ALA Annual Conference, and is now named the ETS Best Free Reference Websites Committee.

A link to this year's list of winners can also be found on the ETS webpage along with a link to the "Best Free Reference Websites Combined Index," which provides, in alphabetical order, all entries from the current and previous seventeen lists. Succinct and insightful annotations for the Best Free Reference Websites List entries were written by committee members in the years the particular websites were selected for the lists. These annotations provide guidance for using the websites as reference tools. Once again, the committee considered free websites in all subject areas useful for ready reference and of value in most types of libraries.

The committee has established the following criteria for nominations:

- Quality, depth, and usefulness of content

- Ready reference

- Uniqueness of content

- Currency of content

- Authority of producer

- Ease of use

- Customer service

- Efficiency

- Appropriate use of the web as a medium

More detailed explanation of the criteria can be found on the ETS webpage (www.ala.org/rusa/sections/mars/mars pubs/marsbestrefcriteria).

As in previous years, the committee worked virtually, using email and the online bookmarking site Diigo (www .diigo.com). Each member nominated five to seven websites using the criteria specified above and then wrote brief annotations that would assist fellow committee members with reviewing and voting for their favorite nominated websites. The goal of this year's committee was to produce a final list with approximately twenty high-quality reference websites. It was a good year in terms of nominations. More than fifty websites were nominated and voting for the best ones was challenging. After careful review, the committee members 


\section{FROM COMMITTEES OF RUSA}

recognized twenty-two new Best Free Reference Websites for 2016. The annotations for winning websites were edited by the co-chairs to ensure that they are of optimal use to librarians and fit the criteria listed above.

\section{BEST WEBSITE WINNERS 2016}

\section{American FactFinder, http://factfinder.census.gov}

This is a search portal for US census and survey information collected by the US Census Bureau, including demographic and economic information. The community facts feature gives quick demographic information about a city, state, zip code, or county. For more complex or specific searches users can choose between a guided search wizard and an advanced search. The three different types of search make this site appropriate for a variety of users.

Author/Publisher: US Census Bureau

Date reviewed: March 13, 2016

\section{AnnualReports.com, www.annualreports.com}

AnnualReports.com bills itself as "the most complete and up-to-date listing of Annual Reports online." Search by company or ticker symbol or browse by alphabetical name, sector, industry, exchange, or index. Once a company is located, its most recent annual report or Form $10-\mathrm{K}$ report can be viewed in HTML or PDF. If it is available, a print annual report will be mailed to a specified address at the user's request. Other information includes a brief description of the company and a short list of similar companies with annual reports on this site. Content is useful for shareholders, investors, company employees, students, and others interested in publically traded companies' financial statements, accomplishments, and goals.

Author/Publisher: AnnualReports.com, a division of IRSolutions.com

Date reviewed: March 9, 2016

\section{Art UK, www.artuk.org}

Art UK provides access to the entire collection of paintings in public ownership at national museums and organizations, local museums, charitable trusts, universities, hospitals, town halls, local libraries, and other civic buildings throughout the United Kingdom. In addition, the site includes works from a number of non-public collections, such as those in the Bishop's Palace (Wells, Somerset, UK) and in Oxford and Cambridge colleges. The vast majority of the works on the site are oil paintings, but works in acrylic and tempera are also included. More than two hundred thousand artworks by 38,370 artists from more than three thousand venues are included. While the majority of artists represented are British artists, a number of artists from other countries are also included, such as Raphael, Claude Monet, and Vincent van Gogh. Project partners include the British Broadcasting Corporation, Oxford University Press, the Public Monuments and Sculpture Association, Culture
24, the Visual Geometry Group at Oxford University and the University of Glasgow.

Author/Publisher: Public Catalogue Foundation

Date reviewed: March 1, 2016

Ballot Measures Database, www.ncsl.org/research/elec tions-and-campaigns/ballot-measures-database.aspx

The Ballot Measures Database is part of the much larger National Conference of State Legislatures website. This database "includes all statewide ballot measures, starting over a century ago" from all types of state elections: General, Primary, and Special. New ballot measures are added to the database when they qualify to be listed on a state's ballot. They are marked "Pass" or "Fail" as soon as election results are available. Browse by state or topic and limit by date. This is a very useful site for anyone interested in locating state issues that have appeared on a state ballot in the last hundred-plus years.

Author/Publisher: National Conference of State Legislatures (NCSL)

Date reviewed: February 24, 2016

Best Commencement Speeches, Ever, http://apps.npr.org /commencement

This web site provides links to over three hundred commencement speeches from 1774 to the present. The speeches can be searched by name, school, or date; or browsed by theme or the name of the presenter. Speech pages include a photograph or illustration of the speaker, the location and year of the speech, a quotation from the speech, the text or a link to the text of the speech on an outside website, and, if available, a video of the speaker presenting the speech. Represented speakers include presidents, politicians, academics, musicians, celebrities, entrepreneurs, journalists, and actors. The site would be useful when needing to write a speech of one's own, to analyze the content of various speeches, or when searching for quotations from speeches.

Author/Publisher: National Public Radio

Date reviewed: January 29, 2016

Cancer Statistics Center, http://cancerstatisticscenter .cancer.org

The Cancer Statistics Center is an interactive website for learning about cancer in the United States. Produced by the American Cancer Society, the site provides statistics on the estimated new cancer cases and deaths by gender, state, and cancer type in the current year; current cancer incidence, mortality, and survival rates and trends; and risk factors (e.g., smoking, obesity) and screening rates by state. The site "aims to serve the needs of cancer control advocates, journalists, government and private public health agencies, and policy makers, as well as patients, survivors and the general public, in order to promote cancer prevention and control."

Author/Publisher: American Cancer Society

Date reviewed: January 29, 2016 


\section{CORE-COnnecting REpositories, http://core.ac.uk}

The mission of CORE (COnnecting REpositories) is to bring together all open access research outputs from repositories and journals throughout the world and make them freely available to the public. CORE provides free, unrestricted access to research for all through harvesting available open access content. Users can search for CORE articles via a comprehensive search engine on the home page or by browsing the latest additions.

Author/Publisher: Knowledge Media Institute

Date reviewed: February 29, 2016

Digital Public Library of America, http://dp.la/subjects

The Digital Public Library of America (DPLA) is a nonprofit organization that is a registered library in the state of Massachusetts. The DPLA offers users the opportunity to search over a million items from collections in libraries, archives, and museums located in the United States. Searches can be conducted by utilizing the search box on top of the website and the user can make use of available timelines, maps, and virtual bookshelves. Apps are available on the App Library webpage. After registering for a free account, the user can save information on a personal bookshelf for later use. The website works with commonly used browsers. Apps for iOS and Android devices are available on the App Library webpage.

Author/Publisher: Digital Public Library of America

Date reviewed: February 23, 2016

Find a Grave, www.findagrave.com

Find a Grave is a free resource for finding the burial places of famous people, family members, and ancestors. The site's mission is to "find, record and present final disposition information from around the world as a virtual cemetery experience." Burial records can be searched by name or by cemetery. Depending on the person, disposition information may include tombstone photos, birth and death dates, biographies, obituaries, family links, and burial location. The site would be useful for genealogists, history buffs, or anyone interested in locating the final resting place of their favorite celebrity.

Author/Publisher: Find a Grave

Date reviewed: March 1, 2016

Global Terrorism Database, www.start.umd.edu/gtd

The Global Terrorism Database (GTD) is an open-source searchable database of information on terrorist events around the world. The site includes systematic data on domestic as well as international terrorist incidents that have occurred from 1970 through 2014 and includes more than 140,000 cases. The database can be searched or browsed by date, region, country, perpetrator group, weapon type, attack type, or target type. For each incident, information is available on the date and location of the incident, the weapons used and nature of the target, the number of casualties, and when available, the group or individual responsible.
Author/Publisher: National Consortium for the Study of Terrorism and Responses to Terrorism

Date reviewed: March 1, 2016

Goodreads, www.goodreads.com

Goodreads provides book recommendations for readers. The website also allows users to list items they have read, want to read, and are currently reading to help keep track of reading lists. Users can browse books by author and view the order of books in a series. Goodreads serves as a social network as well, providing a platform to read other users' book ratings and make book lists to share publicly.

Author/Publisher: Goodreads

Date Reviewed: February 24, 2016

Guide to North American Birds, www.audubon.org /bird-guide

The Guide to North American Birds, part of the National Audubon Society website, describes over one thousand species of birds in North America. Birds can be browsed by species or searched by name or species. Entries provide information on conservation status, scientific classification (family, genus, and species), habitat, photographs, detailed range maps, migration information, and natural history (feeding, breeding, habitat, eggs, young, etc.). Apps are available for iPhones and Android and information can be shared using Facebook, Twitter, Pinterest, and email. An "About" page describes the history and work of the Audubon Society, as well as information about local chapters and birding.

Author/Publisher: National Audubon Society

Date reviewed: February 28, 2016

Internet Encyclopedia of Philosophy, www.iep.utm.edu

The Internet Encyclopedia of Philosophy is a nonprofit organization that provides open access to detailed, scholarly information on key topics and philosophers in all areas of philosophy. The staff of thirty editors and approximately three hundred authors hold doctorate degrees and are professors at colleges and universities around the world (though mostly from English-speaking countries). Submissions are peer-reviewed by specialists according to strict criteria.

Author/Publisher: James Fieser (Editor), University of Tennessee at Martin and Bradley Dowden (Editor), California State University, Sacramento

Date reviewed: March 13, 2016

JournalTOCs, www.journaltocs.ac.uk

JournalTOCs is a very large collection of free tables of contents for subscription and open access scholarly journals. Over 2,800 publishers are represented, including Elsevier, Wiley, Taylor and Francis, Oxford, Cambridge, the American Chemical Society, Project Muse, and the American Psychological Association. Search by journal title or keyword, browse by subject or publisher, or register for a free account to be alerted when journals you elect to follow publish a new issue. This service is especially useful for scholars, students, 


\section{FROM COMMITTEES OF RUSA}

librarians, and others who want to keep up with the articles published in selected journals.

Author/Publisher: School of Mathematical and Computer Science, Heriot-Watt University, Edinburgh, UK

Date reviewed: March 4, 2016

\section{National Parks Service, www.nps.gov}

The National Parks Service (NPS) will celebrate one hundred years of stewardship and engagement in August 2016. The website lists basic park information; celebrates park news and events; hosts educational resources; and provides resources such as over 150 webcams located in parks across the United States. The images and descriptions illustrate the breadth of the NPS; added features such as interactives and webcams provide greater content. Additionally, history and the sciences are represented by fact sheets and projects. Teachers have several options, including distance learning, to use in a K-12 curriculum. The "Kids" page offers opportunities for kids to join junior rangers and web rangers. This website is a reference site in that it provides access to the information needed to visit a park and all the activities available.

Author/Publisher: National Parks Service, US Deptartment of the Interior

Date Reviewed: February 19, 2016

National Transportation Statistics, www.rita.dot.gov /bts/sites/rita.dot.gov.bts/files/publications/national_trans portation_statistics/index.html

National Transportation Statistics presents statistics on the US transportation system. Information includes safety statistics (accident, injuries/fatalities, etc.), energy consumption, air pollution, how transportation relates to the economy (gross domestic product), and much more. Besides traditional motor vehicles, the site also includes data for other modes of transportation such as airlines, watercrafts, and railroads. Data is accessible via HTML, Microsoft Excel, or CSV files. The site is updated quarterly.

Author/Publisher: Bureau of Transportation Statistics

Date reviewed: March 13, 2016

NYPL Digital Collections, http://digitalcollections.nypl.org The New York Public Library has digitized over 650,000 items from their collections and made them searchable in a user-friendly web portal. A variety of different types of media are included in the collection, such as images, text, and streaming video. Contents of the digital collections are extremely varied and include things like images of midcentury Manhattan, cigarette cards, and fashion illustrations. Many of the items in the collection are also available for download, including over 180,000 that are in the public domain. The site is updated daily as more collections are digitized. NYPL also has a number of experimental tools for extracting data from the digital collections that allow users to further explore the materials.

Author/Publisher: New York Public Library

Date reviewed: March 13, 2016
Statistical Abstracts of the United States, www.census .gov/library/publications/time-series/statistical_abstracts .html

This site provides digital copies of the Statistical Abstract of the United States for the years 1878 through 2012, when the Statistical Compendia program ended, with a few omissions (1886, 1890, 1923, 1932, and 1975). Supplements such as the Historical Statistics of the United States, State and Metropolitan Area Data Book, and County and City Data Book are available for some years. The Statistical Abstracts and related supplements are a treasure trove of statistical data useful for students, researchers, and the general public seeking to locate social, political, and economic data for the United States.

Author/Publisher: US Census Bureau

Date reviewed: March 3, 2016

USDA Local Food Directory Listings, www.ams.usda .gov/services/local-regional/food-directories-listings

Maintained by the Agricultural Marketing Service, a division of the United States Department of Agriculture, this site has four directories to search for locally grown food. Users can find nearby farmer's markets, CSA networks, farms, and distributors of locally grown food. Directories are searchable by location, product availability, payment method, and whether or not the market participates in federal nutrition programs.

Author/Publisher: US Department of Agriculture

Date reviewed: March 13, 2016

US Small Business Administration, www.sba.gov

The US Small Business Administration (SBA) is an independent agency of the federal government. It works to provide assistance and aid to small businesses. This site contains educational videos, resource guides, free online classes, and contact information for local agencies. This site is well designed and has a comprehensive search engine.

Author/Publisher: US Small Business Administration

Date reviewed: February 11, 2016

W3Schools, www.w3schools.com

This is one of the premiere reference websites for web developers and designers. In addition to a massive catalog of pages explaining different elements of HTML, JavaScript, PHP, and more, it has built-in tutorials and tasks that users can go through to learn more about web design. There are better places to learn the basics of web design and coding (e.g., Codecademy), but as a reference tool for looking up commands and tools, ranging from very basic to very complex topics, this site has a lot of the information designers and developers need to get started. Furthermore, this site is critically important to both novices and experts.

Author/Publisher: W3Schools-Refsnes Data

Date reviewed: March 1, 2016 